\title{
Research on Rock Fracture Surface Morphology Characterization under Brazilian Test
}

\author{
Zhigang Feng, ${ }^{1,2}$ Xuezai Pan, ${ }^{1,3}$ Guoxing Dai, ${ }^{1}$ and Hongguang Liu ${ }^{4}$ \\ ${ }^{1}$ Faculty of Science, Jiangsu University, Zhenjiang 212013, China \\ ${ }^{2}$ State Key Laboratory of Coal Resources and Safe Mining, China University of Mining and Technology, Beijing 100083, China \\ ${ }^{3}$ School of Mathematics, Taizhou College, Nanjing Normal University, Taizhou 225300, China \\ ${ }^{4}$ Faculty of Civil Engineering and Mechanics, Jiangsu University, Zhenjiang 212013, China \\ Correspondence should be addressed to Xuezai Pan; xzpan1975@163.com
}

Received 2 January 2014; Revised 13 March 2014; Accepted 23 March 2014; Published 28 April 2014

Academic Editor: Dianchen Lu

Copyright (c) 2014 Zhigang Feng et al. This is an open access article distributed under the Creative Commons Attribution License, which permits unrestricted use, distribution, and reproduction in any medium, provided the original work is properly cited.

\begin{abstract}
In order to test the differences in the morphology characterization of rock fracture surfaces under different loading directions and rates, the following three steps are operated. Firstly, using Brazilian test, the Brazilian discs are loaded to fracture under different loading modes. Secondly, each rock fracture surface is scanned with a highly accurate laser profilometer and accordingly the coordinates of three lines on every rock fracture surface and three sections of every line are selected to analyze their fracture morphology characterization. Finally, modulus maximum method of wavelet transform, including a new defined power algorithm and signal to noise ratio, and fractal variation method are used to determine the differences in rock fracture surfaces' morphology characterization under different loading directions and rates. The result illustrates that both modulus maximum and fractal variation method can detect anisotropy of rock fracture failure. Compared to modulus maximum method, fractal variation method shows stronger sensitivity to the change of loading rates, which is more suitable to differentiate the rock fracture surface's morphology characterization under different loading modes.
\end{abstract}

\section{Introduction}

Power analysis has been widely applied in detecting singular points of signal. Furthermore, energy analysis has been being used in rock mechanics analysis and rock engineering so far. The foundational theory of rock fracture failure's energy driver is being explored and developed at the present stage. For the phenomenon of dynamic instability in rock engineering system, some experts have done a lot of research work from experiments and theories. For example, Xie et al. [1-5] researched these concepts of energy dissipation and strength, energy release, and the whole rock mass failure in deformation and fracture process of rock, which illustrates that the damage evolution equation of rock can be used to better describe the damage and evolution process of rock based on energy dissipation analysis. In addition, from energy aspect, the deformation and damage process of rock were analyzed by Xie et al., which indicates that rock failure damage is a result that energies suddenly release and this kind of release is a mutation of energy dissipation under certain conditions. You and Hua [6] used MTS (mechanics testing systems) to load to siltstone samples through conventional triaxial loading and measure axial direction and circumference one stress, the deformation process curve, and energy change in failure process of rock sample, which can conclude that the energy absorption of rock specimen has the same linear relationship with confining pressure through two stress paths reaching shear failure. Hua et al. $[7,8]$ researched that marble was experimented through reducing confining pressure with rigid electrohydraulic servo system and simulated surrounding rock fractured in the excavation process of underground engineering, which revealed that antihypertensive crushing rock is different from pressure crushing rock in energy changes aspect. In the aspect of researching morphology characterization differences under different loading modes, Xie et al. [9-11] creatively applied fractal theory in analyzing morphology of rock fracture surfaces and fractal dimension was used to describe roughness of rock fracture surface, 


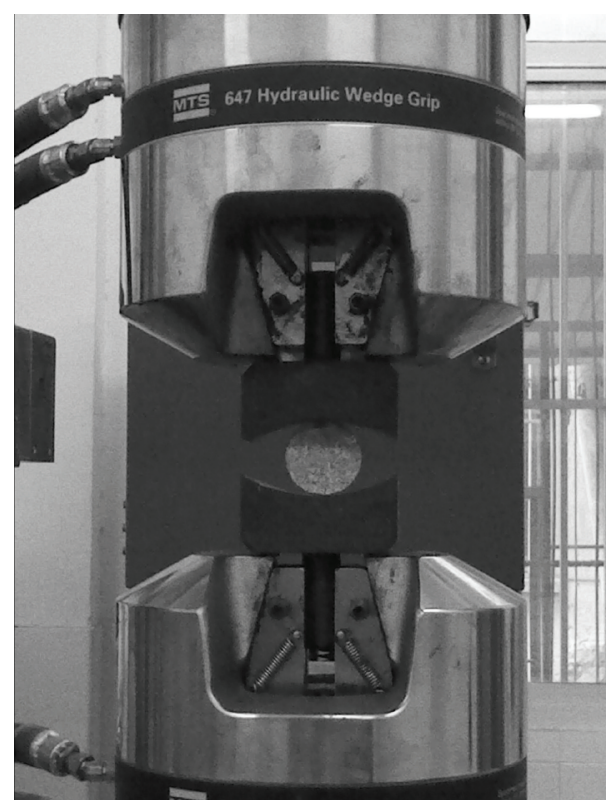

FIGURE 1: Brazil disc loaded with MTS machine.

which can determine morphology differences of rock fracture surfaces under different loading ways. Zhou and Xie [12] utilized signal analysis method to analyze anisotropy on rock fracture surfaces. Belem et al. [13] studied quantitative parameters which were used to describe joint roughness of rock. Rasouli and Harrison [14] described roughness of rock fracture surfaces through linear profile based on Riemann statistics. Rasouli and Harrison [15] researched scale effect and anisotropy of discontinuous surfaces' roughness. BorriBrunetto et al. [16] studied microslip of rock fracture roughness surface under circular tangential loading.

In the paper, in order to differentiate the rock fracture surface's morphology characterization under different loading modes, Brazilian test is used to load Brazilian discs to fracture and the rock fracture surfaces are scanned with a highly accurate laser profilometer. Modulus maximum method and fractal variation method are used to analyze the scanned coordinates data. The result shows that both modulus maximum method and fractal variation method can detect the differences in rock fracture surfaces' morphology characterization under different loading modes. Compared with modulus maximum method, fractal variation method shows more obvious sensitivity to change of loading rates. The following content in structure is divided into five parts, that is, experimental design and operation, acquisition of data and research methods, detailed steps of operation, fractal variation method, and conclusion.

\section{Experimental Design and Operation}

Experiment procedure is arranged in the following content. Firstly, the special granite whose joint is relatively uniform is selected from North Mountain quarry in Gansu province of China. A cylinder-shape rock core with diameter $50 \mathrm{~mm}$ and height $120 \mathrm{~mm}$ is drilled out from large blocks of rock mass

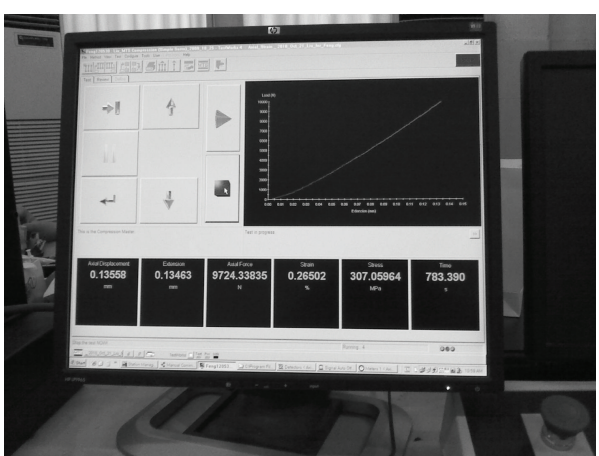

FIGURE 2: Loading intensity displayed on the screen with MTS.

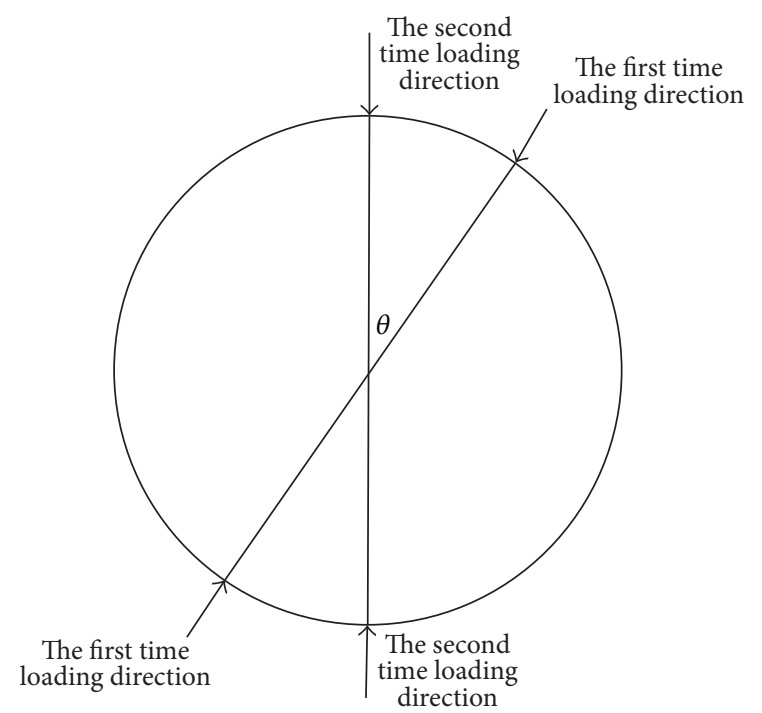

FIGURE 3: Schematic diagram of two times loading through rotating $\theta=30$ degrees.

with model number ZS100 drilling machine. Successively, the three cylinder-shape rock cores are dried with dry oven and cut into Brazilian discs of diameter $50 \mathrm{~mm}$ and height $20 \mathrm{~mm}$ with cutting machine. These Brazilian discs surfaces are smoothed with sander so that the upper and lower surfaces' depth of parallelism is within $0.05 \mathrm{~mm}$ and surface flatness is within $0.2 \mathrm{~mm}$. Secondly, Brazilian discs are pressed to failure fracture along vertical direction under different loading rates with MTS (mechanics testing systems) (refer to Figure 1). Loading rate is $0.01 \mathrm{~mm}$ per minute $(0.01 \mathrm{~mm} / \mathrm{m}), 0.1 \mathrm{~mm}$ per minute $(0.1 \mathrm{~mm} / \mathrm{m})$, and $1 \mathrm{~mm}$ per minute $(1 \mathrm{~mm} / \mathrm{m})$, respectively. In addition, the following experiment is operated. In the first place, rock specimen is compressed to about $13 \mathrm{KN}$ (refer to Figure 2) which is approximately two-thirds of the sort of rock specimens' fracture strength threshold with MTS machine under loading rate $0.01 \mathrm{~mm} / \mathrm{m}$. In the next place, the upper and lower loading fixture of MTS machine are relaxed. Successively, the disc sample is rotated 30 degrees angle around the center of the specimen along the clockwise direction and pressured to fracture (refer to Figure 3 ). The three disc specimens are manipulated in the above every 


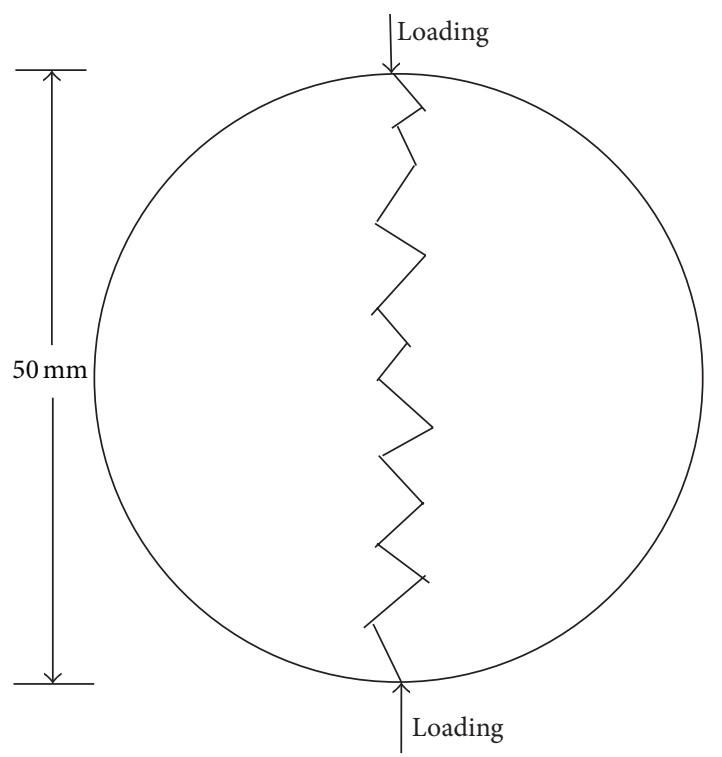

FIGURE 4: Schematic diagram of fractured Brazil disc along upright direction.

loading mode, so the number of testing samples is total 12 . From rock mechanics principle, Brazilian test belongs to a kind of indirect tension. That is to say, these Brazilian discs are indirectly tensile towards both sides along the horizontal direction until these discs are fractured from center line along vertical direction (refer to Figure 4).

\section{Acquisition of Data and Research Methods}

3.1. Acquiring Coordinate Data of Rock Fracture Surface. Because 3D figure of rock fracture surface (refer to Figure 5) is very rough and irregular, a highly accurate rock laser profilometer (refer to Figure 6) is used to scan rock fracture structure surface. Based on scanning rock fracture structure surface and numerical method, it is considered that morphologies among rock fracture surfaces are different and scanned data are complete and comparable, so the coordinate data of three lines and three sections of every line on the same fracture surface are selected to research morphology characteristic differences of rock fracture surfaces. The three straight lines in the center part on rock fracture surface are divided into left, middle, and right line, respectively, and their interval is $0.1 \mathrm{~mm}$ from left to right (refer to Figure 7). On the other hand, each line is divided into three sections and each section length is equal to 512 data points, that is, 100 612, 200 712, and 300 812 (refer to Figure 7). After acquiring sampling data of rock fracture surface, tests on sample's loading directions and variation of loading rates are researched based on the theory of singular signal testing in modulus maximum method of wavelet transform. Successively, singular points of data signal are positioned through computational procedure. The data extracted by computer are computed as modulus maximum value and reconstructed signal by calculating. Based on the above steps, a new concept of calculating power is defined and powers of

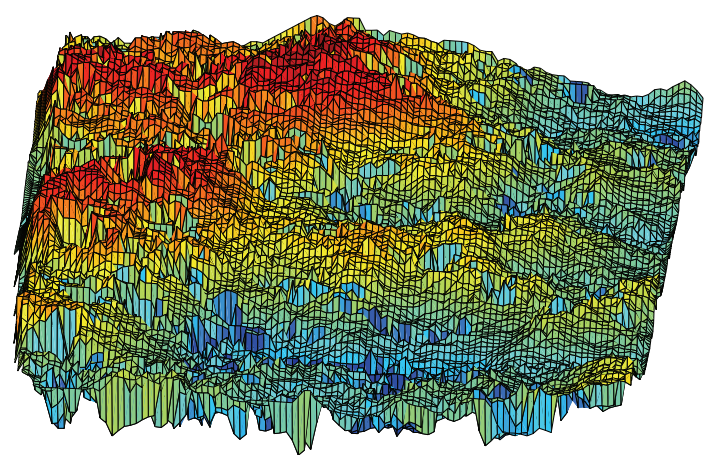

FIGURE 5: 3D figure of rock fracture surface.

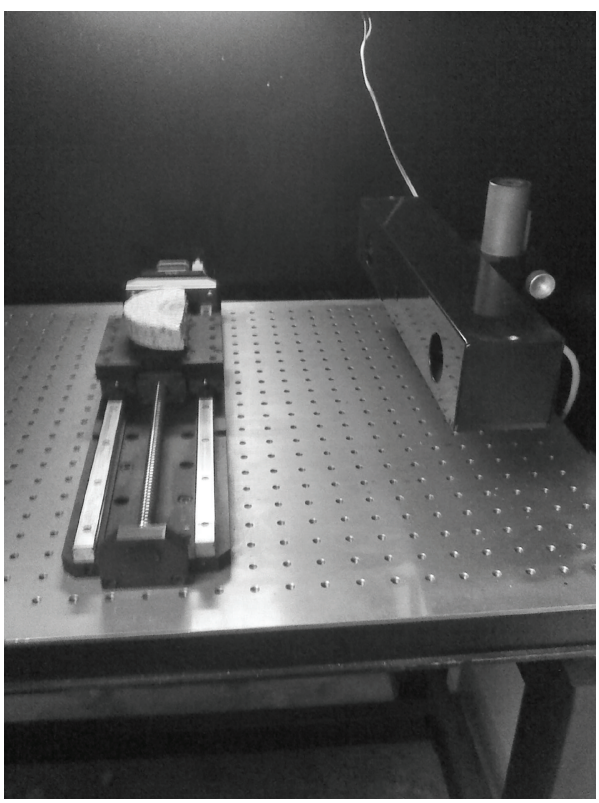

FiguRE 6: Highly accurate laser profilometer.

these specimens are computed according to the new power definition. Furthermore, corresponding signal to noise ratios are calculated through reconstruction signals. For the new defined power and signal to noise ratio, two methods which are generated through the two new concepts can effectively distinguish a morphology of rock fracture surface under one loading direction from that of another loading direction, but they cannot describe the differences between a morphology of rock fracture surface under one loading rate and that of another loading rate.

\subsection{Research Method}

\subsubsection{Modulus Maximum Theory of Wavelet Transform}

Definition 1 (see [17]). Let $w_{f}(a, x)$ be a convolution type of wavelet transform of function $f$; if $\partial w_{f}\left(a_{0}, x\right) / \partial x$ is equal to 


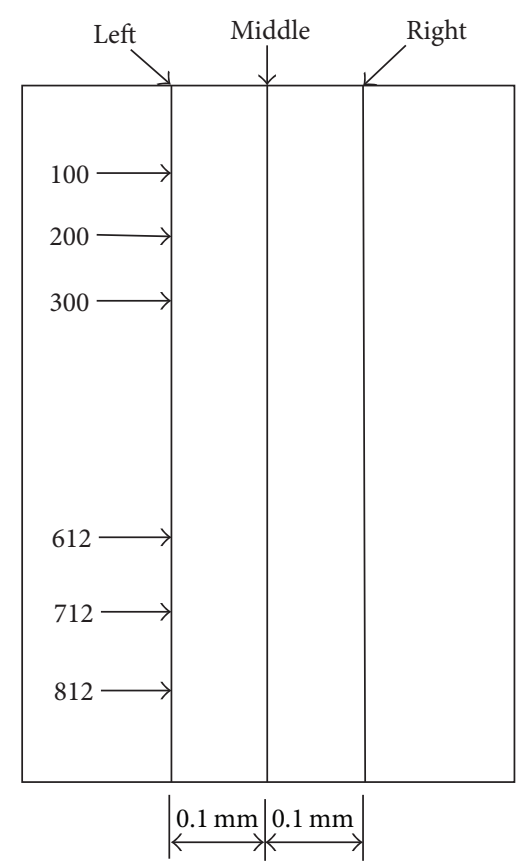

Figure 7: Schematic diagram of extracted three lines and three sections of every line.

zero on $x_{0}$ under the scale $a_{0}$, then point $\left(a_{0}, x_{0}\right)$ is called local value point. If, for all $x \in U\left(x_{0}, \delta\right)$, it satisfies inequality

$$
\left|w_{f}\left(a_{0}, x\right)\right| \leq\left|w_{f}\left(a_{0}, x_{0}\right)\right|,
$$

then $\left(a_{0}, x_{0}\right)$ is called modulus maximum value point of wavelet transform.

3.2.2. Principle of Modulus Maximum. The advantage that maximum value of $w_{f}(a, x)$ is used to characterize signal is that it can distinguish maximum value from minimum one. It is one of the foundational theories of signal's mutation point tested by wavelet transformation that variation of signal at maximum point is sharp and variation of signal at minimum point is slow, so corresponding positions of wavelet coefficients' modulus maximum points and mutation ones are determined easily. However, because wavelet coefficients are affected by noise under small scales, a lot of pseudoextreme value points are often generated by noise. Conversely, noise signals are dealt with certain smoothness under large scales, so extreme points are relatively stable. Correct scale needs to be selected to analyze wavelet transformation in practice in case of overlapped interference. While modulus maximum method of wavelet transformation is used to deal with rock fracture surface, several scales need to be combined in order to consider effect of comprehensive experiment. Under variation of loading directions and accelerated actions, relatively stable characterization of extreme points is researched by wavelet transformation under large scale.

\section{Detailed Steps of Operation}

4.1. Acquiring Data and Handling Files. After sampling coordinate data of three lines and three sections on each line being acquired, corresponding procedure files are edited. Successively, the following content deals with wavelet transform procedure.

Let $f(n T), n=1,2, \ldots, M$ be discrete sampling data of three lines and three sections on each line on rock fracture surface, where $M$ is the number of sampling points and $T$ is sampling interval. Let points $=512$, level $=6, \mathrm{sr}=360$, num_iterated $=6$, wf = "db9", which denotes length of data handled, decomposed ranks, sampling rate, iterative times, and name of wavelet, respectively. $f(n T), n=1,2, \ldots, M$ is regarded as original signal to be decomposed with 6 layers; thus, approximate coefficients and detailed ones could be obtained.

4.2. Recognizing Sequence Files' Identification and Plotting Figures. This sequence files' identification "A1(R), A2(R), $\mathrm{A} 3(\mathrm{R}), \mathrm{A1}, \mathrm{A} 2, \mathrm{~A} 3, \mathrm{~B} 1, \mathrm{~B} 2, \mathrm{~B} 3, \mathrm{C} 1, \mathrm{C} 2, \mathrm{C} 3$ " is read by computer program, where "A, B, C" denotes MTS loading rate $0.01 \mathrm{~mm} / \mathrm{m}, 0.1 \mathrm{~mm} / \mathrm{m}$, and $1 \mathrm{~mm} / \mathrm{m}$, respectively; " $1,2,3$ " shows the label number of specimen, respectively. "R" denotes the specimens which are rotated 30 degrees around center of Brazil disc along with clockwise. The above data files are done with wavelet transform; therefore, linear interpolation figure and detailed wave shape plot are plotted. For example, for the identification $\mathrm{Al}(\mathrm{R})$ of specimen, the original signal plot and the wavelet decomposed plot of its middle profile are shown in Figure 8.

4.3. Evaluating Modulus Maximum and Its Position of Wavelet Transform. From Figure 9, the following conclusion is obtained that the amplitudes and numbers of some singularities decrease level by level along with increase of scale and singular points mainly concentrate on high frequency parts of $d 1$ and $d 2$. In addition, modulus maximum points are almost completely controlled by such singular points.

4.4. Computing Wavelet Decomposed Coefficients and Sequence of Modulus Maximum. Wavelet coefficients of each layer and positions of modulus maximum points are noted, respectively, by the following two signs: $a_{i j}=s w a(i, j)$, $w_{i, j}=w_{\text {peak }}(i, j), i=1,2, \ldots, 512 ; j=1,2, \ldots, 6$. Successively, original signal is compared with modulus maximum reconstruction signal.

4.5. Computing Signal to Noise Ratio of Reconstruction Wavelet and Original Signal. Original signal wavelet transform (OSWT) is compared with reconstruction wavelet transform (RWT) and error between them is calculated by the following formula:

$$
\text { Error }=\operatorname{RWT}(1: \text { points })-\operatorname{OSWT}(1: \text { points }) \text {, }
$$

where "points" are reserved modulus maximum point.

Signal to noise ratio (snr) is used to compare a kind of rock fracture morphology difference with that of another one 

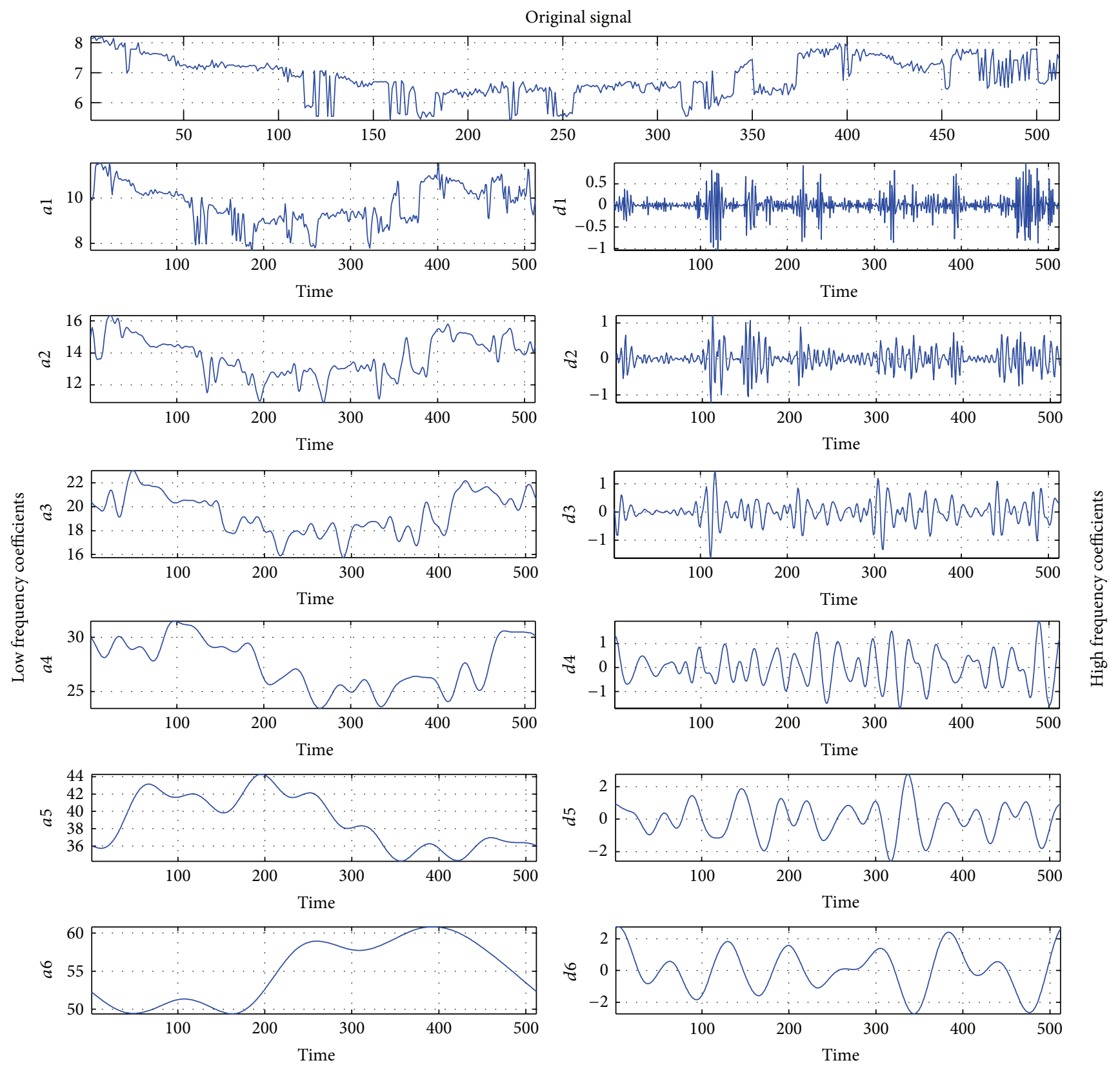

The length of data points

FIGURE 8: Original signal and six-layer wavelet decomposition of middle profile with $A 1(R)$.

under different loading modes. snr is computed through the following formula:

$$
\operatorname{snr}=20 * \lg \left(\frac{\text { norm }(\text { Signal })}{\text { norm }(\text { Error })}\right)
$$

4.6. Counting the Number of Extreme Points and Defining a New Power. Extreme points of $w_{i j}=w_{\text {peak }}(i, j)$ are counted and a new definition of power is defined by the following formula:

$$
\text { topow }=\sqrt{\frac{\sum_{j=1}^{6} \sum_{i=1}^{M} a_{i j}^{2} \cdot\left|w_{i j}\right|}{M}}
$$

where topow denotes the new definition of power and $a_{i j}=$ swa $(i, j)$. While $w_{\text {peak }}(i, j)$ is extreme value point, then $w_{i j}=$ 1 , if not, then $w_{i j}=0, i=1,2, \ldots, M, j=1,2, \ldots, 6$; where $M=512$. The computational results of each specimen are shown in Table 1. 


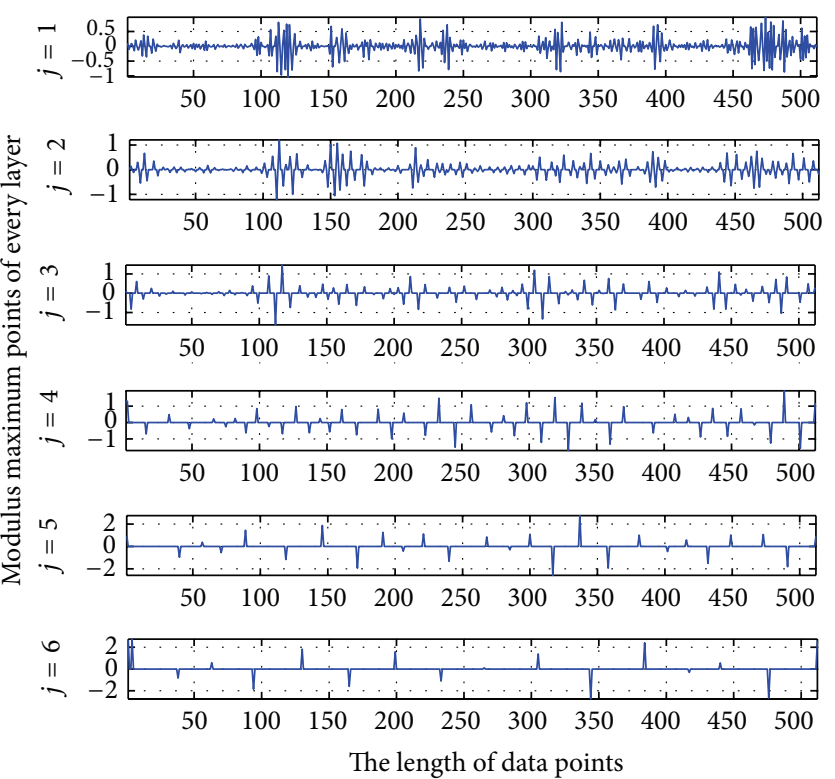

Figure 9: Modulus maxima and their positions of each layer high frequency coefficients with $\mathrm{Al}(\mathrm{R})$.

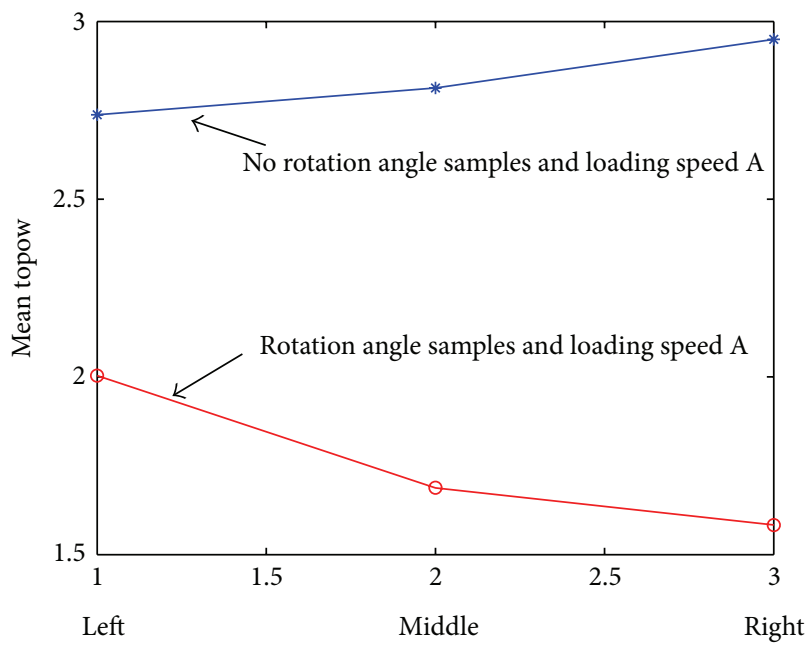

FIGURE 10: The mean topow of rotation and no rotation specimens under loading speed A.

From Table 1, four conclusions can be concluded in the following content. Firstly, for three lines and three sections of every line on the same specimen fracture surface, errors among their topow are very small and errors among their snr are very small too, which indicates that the calculation of topow and snr has nothing to do with positions of extracted lines on the same specimen fracture surface. Secondly, the mean of three lines and three sections' topow on fracture surfaces of specimens not rotated is obviously greater than that of specimens rotated 30 degrees (refer to Figure 10), where "1, 2, 3" in Figure 10 denotes three profile curves of "left, middle, right," respectively (the same signs are in Figures 11, $12,13,14$, and 15). In addition, the variation of snr is on the whole same as that of topow (refer to Figure 11). From the

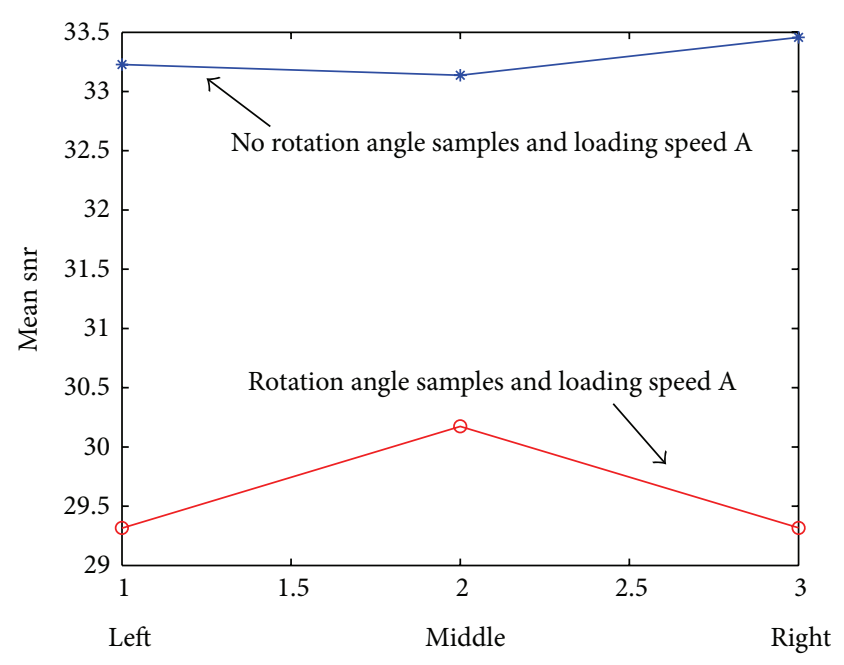

FIGURE 11: The mean snr of rotation and no rotation specimens under loading speed A.

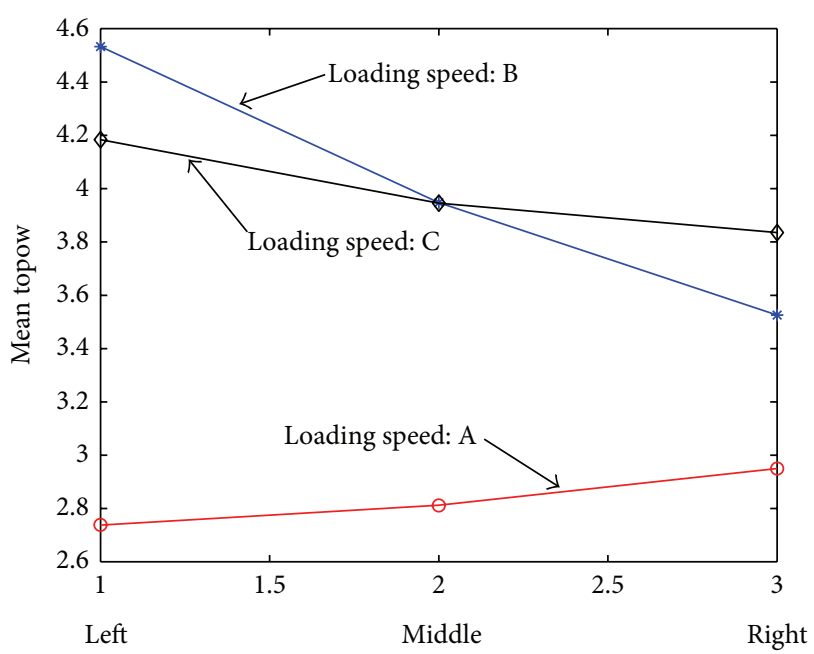

FIGURE 12: The mean topow of rock specimens under loading speed A, B, C.

variable regularity of topow and snr, it can be acquired that specimens compressed to $13 \mathrm{KN}$ did not fracture before being rotated 30 degrees, but the inners of rock specimens have been damaged to a certain extent. Finally, specimens are not rotated angle, but loading rates changed. The mean's variation of three lines and three sections' topow and snr on fracture surfaces of specimens loaded speeds with A $(0.01 \mathrm{~mm} / \mathrm{m}), \mathrm{B}$ $(0.1 \mathrm{~mm} / \mathrm{m})$, and $\mathrm{C}(1 \mathrm{~mm} / \mathrm{m})$ is shown in Figures 12 and 13 .

From Figures 12 and 13, the mean's plot of topow and snr has intersected severally and do not show obvious regularity, which illustrates the change of loading rates did not obviously affect the mean's change of topow and snr. So, topow and snr have no obvious effect to distinguish a kind of characterization of rock fracture surface caused by a loading behavior from that of another behavior. 


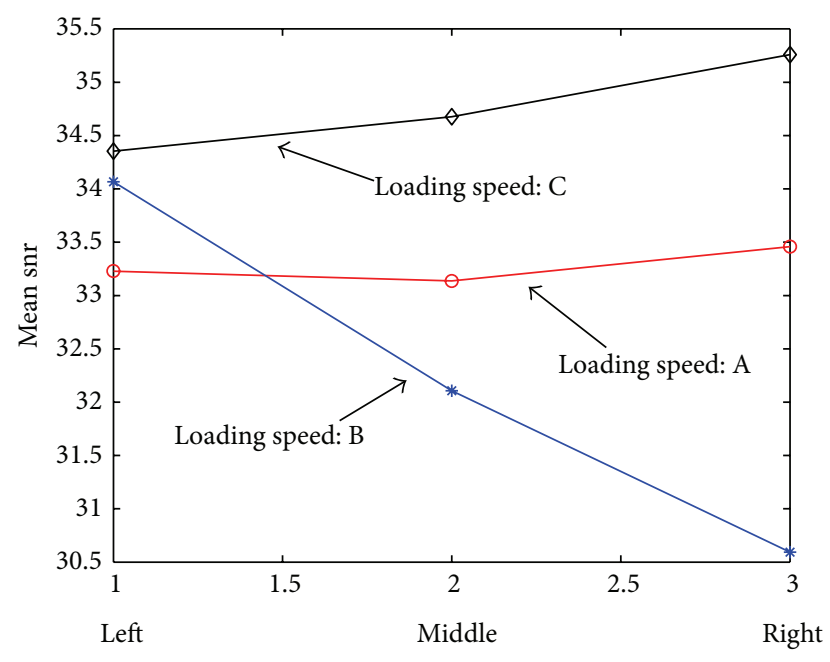

FIGURE 13: The mean snr of rock specimens under loading speed A, B, C.

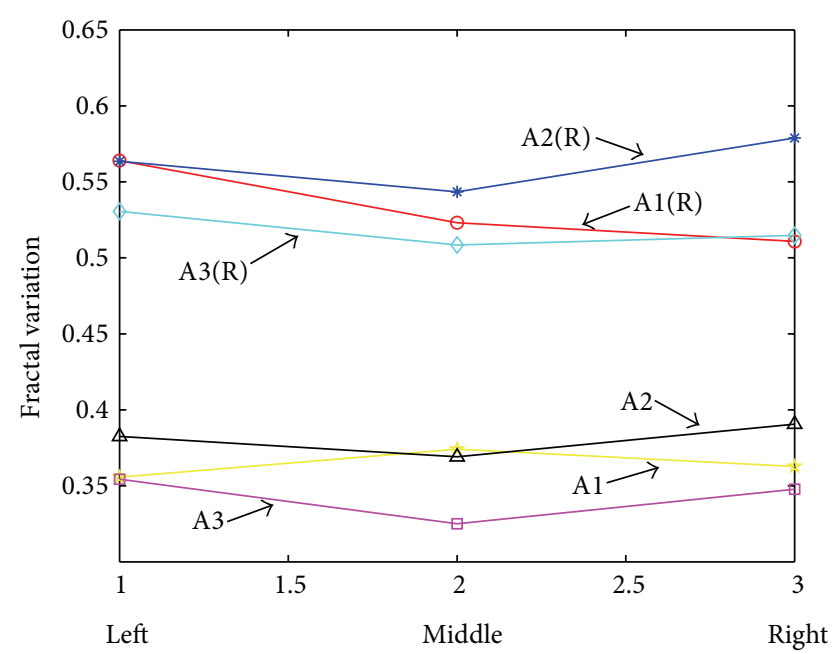

FIGURE 14: The variation plot of rotation and no rotation specimens under loading rate $\mathrm{A}$.

\section{Fractal Variation Method}

Fractal variation can reflect undulated extent of profile on rock fracture surface and roughness. In the same scale, the bigger fractal variation is, the rougher profile is. Conversely, the smaller fractal variation is, the smoother profile is. For the above extracted three lines and three sections of each line, the mean of three lines variation including left, middle, and right line is computed, respectively. For example, for left line data points, ordinal every five points is regarded as an interval from the first abscissa point 100 to 612, so the total data points can be divided into 103 groups and the last group has only three points. The distance between ordinate value of the highest point and that of the lowest one in the $i$ th group is regarded as variation of the $i$ th group. And then the average of all variations summation is computed with

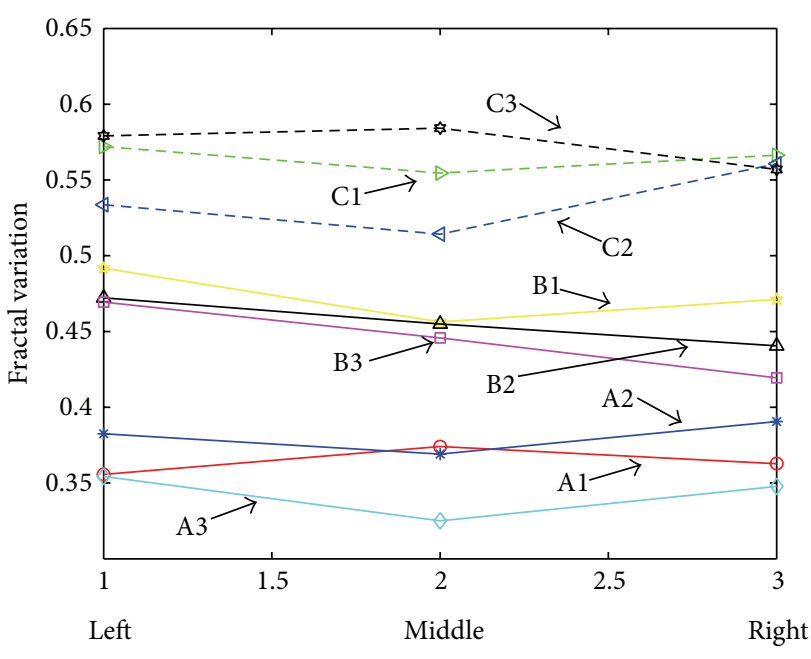

FIGURE 15: The variation plot of specimens under loading rates A, B, C.

computer program, which denotes the variation of the profile curve. It is expressed through the following formula:

$$
V=\frac{1}{N} \sum_{i=1}^{N}\left|z_{i+5}-z_{i}\right|,
$$

where $V$ denotes variation. $z_{i+5}, z_{i}$, respectively, denotes ordinate value of the highest point and the lowest one every five points. $N$ indicates the number of groups, where $N=$ 103. The variations of all specimens' profiles are shown in Table 2.

From Table 2, the conclusion is obtained from the following three aspects. Firstly, three profiles' variation scope of specimens $\mathrm{A} 1(\mathrm{R}), \mathrm{A} 2(\mathrm{R})$, and $\mathrm{A} 3(\mathrm{R})$ rotated 30 degrees is from 0.5085 to 0.5788 . Three profiles' variation range of specimens A1, A2, and A3 is from 0.3250 to 0.3906 and those of specimens B1, B2, and B3 is from 0.4194 to 0.4918 . Moreover, variation range of specimens $\mathrm{C} 1, \mathrm{C} 2$, and $\mathrm{C} 3$ is from 0.5142 to 0.5842 . Secondly, under the same loading rate $\mathrm{A}=0.01 \mathrm{~mm} / \mathrm{m}$, due to $0.3250 \sim 0.3906<0.5085 \sim 0.5788$, the variation scope of specimens not rotated angle is smaller than that of specimens rotated 30 degrees. The variation plot of specimens rotated 30 degrees is higher than that of specimens not rotated angle in Figure 14, which illustrates that rock sample compressed to $13 \mathrm{KN}$ has not been fractured before being rotated angle, but the inner of the specimen has been damaged to a certain extent. That is to say, the loading deviating 30 degrees direction has made cements among grains in rock inner become loosened, which made undulated extent of fracture surface become large and indicates range of variation promoted. The result illustrates that loading mode rotated angle affects roughness of rock fracture surface to a certain extent and fractal variation method could distinguish morphology characterization of rock fracture surface caused by loading mode rotated angle from that of loading mode not rotated angle. Finally, variation range of profiles will increase along with increase of loading rates. Refer with Figure 15, variation curves of specimens under different loading rates 
TABLE 1: The topow and snr values of every rock specimen's three lines and three sections.

\begin{tabular}{|c|c|c|c|c|c|c|c|}
\hline \multirow{2}{*}{$\begin{array}{l}\text { Type (512) } \\
\text { Specimen name }\end{array}$} & \multicolumn{2}{|c|}{$100 \sim 612$} & \multicolumn{2}{|c|}{$200 \sim 712$} & \multicolumn{2}{|c|}{$300 \sim 812$} & \multirow{2}{*}{ Remarks } \\
\hline & topow & snr & topow & snr & topow & snr & \\
\hline \multicolumn{8}{|l|}{$\mathrm{A} 1(\mathrm{R})$} \\
\hline Left & 2.1177 & 28.2085 & 2.1159 & 25.9393 & 1.5968 & 24.4652 & \multirow{10}{*}{ Rotating 30 degrees and loading rate $0.01 \mathrm{~mm} / \mathrm{min}$} \\
\hline Middle & 1.9712 & 28.2180 & 1.4164 & 28.2495 & 1.2095 & 25.5551 & \\
\hline Right & 1.1781 & 23.9738 & 0.9639 & 25.7714 & 1.1781 & 23.9738 & \\
\hline \multicolumn{8}{|l|}{$\mathrm{A} 2(\mathrm{R})$} \\
\hline Left & 2.2407 & 34.5297 & 2.5247 & 34.3279 & 2.4520 & 33.4213 & \\
\hline Middle & 1.7688 & 33.1245 & 1.7326 & 33.3074 & 1.9929 & 32.0687 & \\
\hline Right & 1.8081 & 35.3026 & 2.0011 & 34.5894 & 2.2370 & 33.5251 & \\
\hline \multicolumn{7}{|l|}{$\mathrm{A} 3(\mathrm{R})$} & \\
\hline Left & 1.3008 & 25.9557 & 1.5986 & 28.4603 & 2.0848 & 28.5200 & \\
\hline Middle & 1.2364 & 29.0886 & 1.8016 & 31.4957 & 2.0572 & 30.4524 & \\
\hline Right & 0.9757 & 26.4687 & 1.8781 & 29.7323 & 2.0301 & 30.5159 & \\
\hline \multicolumn{7}{|l|}{ A1 } & \multirow{12}{*}{ No rotation and loading rate $0.01 \mathrm{~mm} / \mathrm{min}$} \\
\hline Left & 3.2335 & 35.8754 & 3.4921 & 34.3184 & 2.9084 & 34.0172 & \\
\hline Middle & 2.8837 & 33.9835 & 2.9557 & 36.4159 & 2.3353 & 37.2918 & \\
\hline Right & 3.3140 & 33.9046 & 2.9990 & 35.7784 & 2.5138 & 38.4240 & \\
\hline \multicolumn{7}{|l|}{$\mathrm{A} 2$} & \\
\hline Left & 2.0933 & 33.1073 & 2.3662 & 32.2579 & 1.8722 & 32.4429 & \\
\hline Middle & 3.0269 & 32.2409 & 3.2957 & 30.4491 & 2.2001 & 31.3141 & \\
\hline Right & 2.9895 & 31.5269 & 3.1478 & 32.4344 & 2.8276 & 31.6690 & \\
\hline \multicolumn{7}{|l|}{ A3 } & \\
\hline Left & 3.2394 & 33.0318 & 2.9002 & 32.3656 & 2.5331 & 31.6309 & \\
\hline Middle & 3.2955 & 32.5780 & 2.9246 & 31.7607 & 2.3966 & 32.2033 & \\
\hline Right & 2.8644 & 34.1870 & 3.1070 & 31.8447 & 2.7851 & 31.3484 & \\
\hline \multicolumn{7}{|l|}{$\mathrm{B} 1$} & \multirow{12}{*}{ No rotation and loading rate $0.1 \mathrm{~mm} / \mathrm{min}$} \\
\hline Left & 5.8236 & 38.1822 & 6.8673 & 38.6366 & 6.0365 & 36.8738 & \\
\hline Middle & 5.6538 & 36.8858 & 6.0551 & 35.0675 & 5.2399 & 33.8614 & \\
\hline Right & 4.8311 & 37.2445 & 4.6722 & 37.3302 & 5.1064 & 34.4377 & \\
\hline \multicolumn{7}{|l|}{ B2 } & \\
\hline Left & 1.3639 & 30.6591 & 1.9368 & 31.6115 & 2.4064 & 33.5190 & \\
\hline Middle & 1.0666 & 25.6068 & 1.4060 & 29.8606 & 2.2827 & 32.0451 & \\
\hline Right & 0.5385 & 20.5109 & 1.5407 & 25.3466 & 2.7123 & 29.6432 & \\
\hline \multicolumn{7}{|l|}{ B3 } & \\
\hline Left & 5.2237 & 32.8384 & 5.5274 & 32.2433 & 5.6112 & 32.0337 & \\
\hline Middle & 4.5047 & 32.7908 & 4.8225 & 31.1635 & 4.4957 & 31.6812 & \\
\hline Right & 4.1084 & 30.3081 & 4.0325 & 30.6452 & 4.1887 & 29.8764 & \\
\hline \multicolumn{7}{|l|}{$\mathrm{C} 1$} & \multirow{12}{*}{ No rotation and loading rate $1 \mathrm{~mm} / \mathrm{min}$} \\
\hline Left & 3.6874 & 35.6802 & 3.3102 & 36.3793 & 3.4515 & 32.1720 & \\
\hline Middle & 3.4373 & 35.3418 & 3.9961 & 33.5528 & 2.9594 & 31.7523 & \\
\hline Right & 4.0881 & 35.7650 & 4.0754 & 35.7602 & 3.7765 & 34.4293 & \\
\hline \multicolumn{7}{|l|}{$\mathrm{C} 2$} & \\
\hline Left & 3.3973 & 32.1173 & 4.2992 & 33.2094 & 3.0814 & 33.8700 & \\
\hline Middle & 3.4003 & 33.1038 & 3.2635 & 33.7587 & 2.8532 & 33.5898 & \\
\hline Right & 3.0218 & 34.3600 & 3.1333 & 34.0173 & 2.3638 & 37.2279 & \\
\hline $\mathrm{C} 3$ & & & & & & & \\
\hline Left & 5.2012 & 35.4596 & 5.3326 & 34.6403 & 5.8940 & 35.6516 & \\
\hline Middle & 4.2759 & 39.1679 & 5.204410 & 37.4150 & 6.1175 & 34.4048 & \\
\hline Right & 4.8863 & 36.5049 & 4.4451 & 36.4781 & 4.7254 & 32.7833 & \\
\hline
\end{tabular}


TABLE 2: The variation mean of every specimen's three lines and three sections.

\begin{tabular}{|c|c|c|c|c|c|c|c|c|c|}
\hline & Left & Middle & Right & Left & Middle & Right & Left & Middle & Right \\
\hline & & $\mathrm{Al}(\mathrm{R})$ & & & $\mathrm{A} 2(\mathrm{R})$ & & & A3(R) & \\
\hline \multirow[t]{2}{*}{ V } & 0.5640 & 0.5231 & 0.5108 & 0.5635 & 0.5434 & 0.5788 & 0.5306 & 0.5085 & 0.5148 \\
\hline & & $\mathrm{A} 1$ & & & A2 & & & A3 & \\
\hline \multirow[t]{2}{*}{ V } & 0.3557 & 0.3741 & 0.3628 & 0.3825 & 0.3691 & 0.3906 & 0.3543 & 0.3250 & 0.3478 \\
\hline & & B1 & & & $\mathrm{B} 2$ & & & B3 & \\
\hline \multirow[t]{2}{*}{ V } & 0.4918 & 0.4563 & 0.4712 & 0.4722 & 0.4549 & 0.4405 & 0.4694 & 0.4458 & 0.4194 \\
\hline & & $\mathrm{C} 1$ & & & $\mathrm{C} 2$ & & & $\mathrm{C} 3$ & \\
\hline V & 0.5720 & 0.5545 & 0.5664 & 0.5337 & 0.5142 & 0.5607 & 0.5791 & 0.5842 & 0.5569 \\
\hline
\end{tabular}

have obvious ranks. Because of $0.3250 \sim 0.3906<0.4194 \sim$ $0.4918<0.5142 \sim 0.5842$, the greater undulated extent of rock fracture surface is, the greater loading rate is; thus, specimen fracture surface becomes more rougher. So, fractal variation method can obviously recognize morphology characterization's differences of rock sampling fracture surface under different loading rates.

\section{Conclusion}

Based on testing 3D rock sampling failure fracture structural surface and carrying out numerical method, for rock samplings of two times rotating loading and variable loading rates, three lines and three sections of every line on rock sampling fracture surface are extracted to research morphology characterization of rock fracture surface through defining a new power algorithm with modulus maximum method of wavelet transform.

Firstly, through modulus maximum method and fractal variation one, the characterization of rock fracture failure behavior provides distinct anisotropy. For the same rock sampling structure, as the same loading mode is selected to test morphology characterization of rock fracture surface, morphology characterization appears obvious change along with the change of loading angles. That is to say, the selfdefined power algorithm's mean of specimens rotated angle is lower than that of specimens not rotated angle and signal to noise ratio has the same varied regularity too. In addition, fractal variation of specimens rotated angle is greater than that of specimens not rotated angle. From rock mechanics principle aspect, rock sampling compressed to $13 \mathrm{KN}$ before being rotated angle does not fracture, but the inner of rock sampling has been damaged and cements among grains have become loosened. And a large number of microcracks occurred in the inner of rock specimen.

Secondly, the characterization of rock fracture failure behavior provides accelerated different characterization. For the same rock sampling, as the same loading mode is selected to test morphology characterization of rock fracture surface, morphology characterization does not appear to obviously varied regularity along with the change of loading rates according to self-defined power and signal to noise ratio, but fractal variation method can recognize different morphology characterizations of rock fracture surfaces under different loading rates, which indicates that sensitivity of fractal variation's change to loading rates is greater than that of modulus maximum method.

Finally, through comparing fractal variation method with modulus maximum one, the advantage of fractal variation method lies in the case that it can recognize morphology characterizations' differences of rock fracture surfaces caused by loading rates' change. However, self-defined power and signal to noise ratio have no obvious effect for the testing.

\section{Conflict of Interests}

The authors declare that there is no conflict of interests regarding the publication of this paper.

\section{Acknowledgments}

This work is supported by the National Natural Science Foundation of China (no. 51079064), the State Key Laboratory of Coal Resources and Safe Mining, China University of Mining and Technology (no. SKLCRSM10KFA02), the Scientific Research Innovation Foundation for Graduate Students of Jiangsu Province (no. CXZZ13_0686), and the Nanjing Normal University Taizhou College Youth Fund Project (no. Q201234).

\section{References}

[1] H. P. Xie, Y. Ju, L. Y. Li, and R. D. Peng, "Energy mechanism of deformation and failure of rock masses," Chinese Journal of Rock Mechanics and Engineering, vol. 27, no. 9, pp. 1729-1740, 2008 (Chinese).

[2] H. P. Xie, R. D. Peng, Y. Ju, and H. W. Zhou, "Energy analysis of rock failure," Chinese Journal of Rock Mechanics and Engineering, vol. 24, no. 15, pp. 2603-2608, 2005 (Chinese).

[3] H. P. Xie, R. D. Peng, and Y. Ju, "Energy dissipation of rock deformation and fracture," Chinese Journal of Rock Mechanics and Engineering, vol. 23, no. 21, pp. 3565-3570, 2004 (Chinese).

[4] H. P. Xie, R. D. Peng, H. W. ZHou, and Y. Ju, "Research advances of rock strength theory based on fracture mechanics and damage mechanics," Progress in Natural Science, vol. 14, no. 10, pp. 1086-1092, 2004.

[5] H. P. Xie, Y. Ju, and L. Y. Li, "Criteria for strength and structural failure of rocks based on energy dissipation and energy release principles," Chinese Journal of Rock Mechanics and Engineering, vol. 24, no. 17, pp. 3003-3010, 2005 (Chinese). 
[6] M. Q. You and A. Z. Hua, "Energy analysis on failure process of rock specimens," Chinese Journal of Rock Mechanics and Engineering, vol. 21, no. 6, pp. 778-781, 2002 (Chinese).

[7] A. Z. Hua, "Energy analysis of surrounding rocks in underground engineering," Chinese Journal of Rock Mechanics and Engineering, vol. 22, no. 7, pp. 1054-1059, 2003 (Chinese).

[8] A. Z. Hua, Y. B. Kong, S. P. Li, and Y. S. Li, "Energy analysis of depressurized rock fracture," Journal of Coal Society, vol. 20, no. 4, pp. 389-392, 1995.

[9] H. P. Xie, Fractals in Rock Mechanics, A.A. Balkema, Leiden, The Netherlands, 1993.

[10] H. P. Xie, H. Q. Sun, Y. Ju, and Z. Feng, "Study on generation of rock fracture surfaces by using fractal interpolation," International Journal of Solids and Structures, vol. 38, no. 32-33, pp. 5765-5787, 2001.

[11] H. P. Xie, J. A. Wang, and M. A. Kwaśniewski, "Multifractal characterization of rock fracture surfaces," International Journal of Rock Mechanics and Mining Sciences, vol. 36, no. 1, pp. 19-27, 1999.

[12] H. W. Zhou and H. P. Xie, "Anisotropic characterization of rock fracture surfaces subjected to profile analysis," Physics Letters A: General, Atomic and Solid State Physics, vol. 325, no. 5-6, pp. 355-362, 2004.

[13] T. Belem, F. Homand-Etienne, and M. Souley, "Quantitative parameters for rock joint surface roughness," Rock Mechanics and Rock Engineering, vol. 33, no. 4, pp. 217-242, 2000.

[14] V. Rasouli and J. P. Harrison, "Assessment of rock fracture surface roughness using Riemannian statistics of linear profiles," International Journal of Rock Mechanics and Mining Sciences, vol. 47, no. 6, pp. 940-948, 2010.

[15] V. Rasouli and J. P. Harrison, "Scale effect, anisotropy and directionality of discontinuity surface roughness," in Proceedings of the Eurock Symposium, pp. 751-756, 2000.

[16] M. Borri-Brunetto, A. Carpinteri, S. Invernizzi, and M. Paggi, "Micro-slip of rough surfaces under cyclic tangential loading," in Analysis and Simulation of Contact Problems, U. Nachenhorst, Ed., vol. 27 of Lecture Notes in Applied and Computational Mechanics, pp. 333-340, Springer, Berlin, Germany, 2006.

[17] F. S. Chen, Application in Signal Process with Wavelet Transform, National Defence Industry Press, Beijing, China, 2001. 


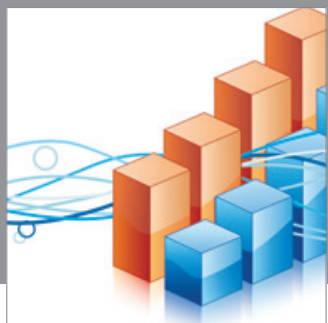

Advances in

Operations Research

mansans

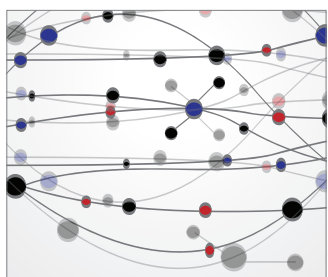

The Scientific World Journal
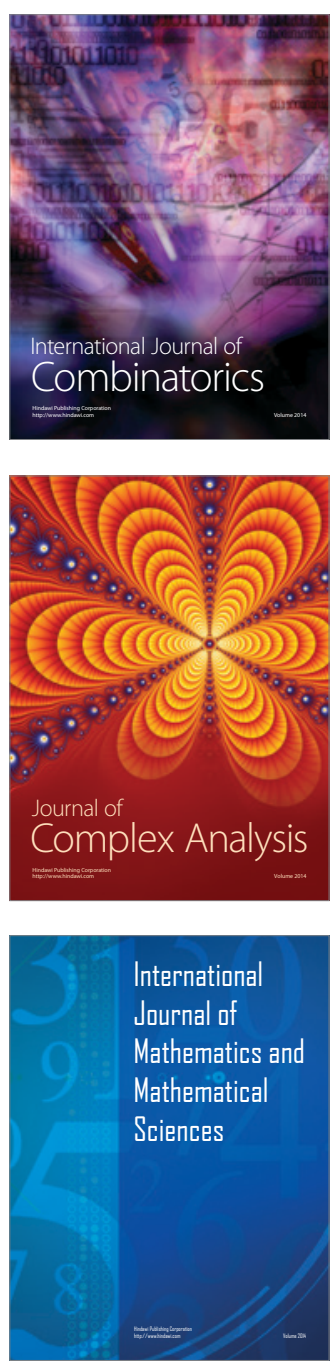
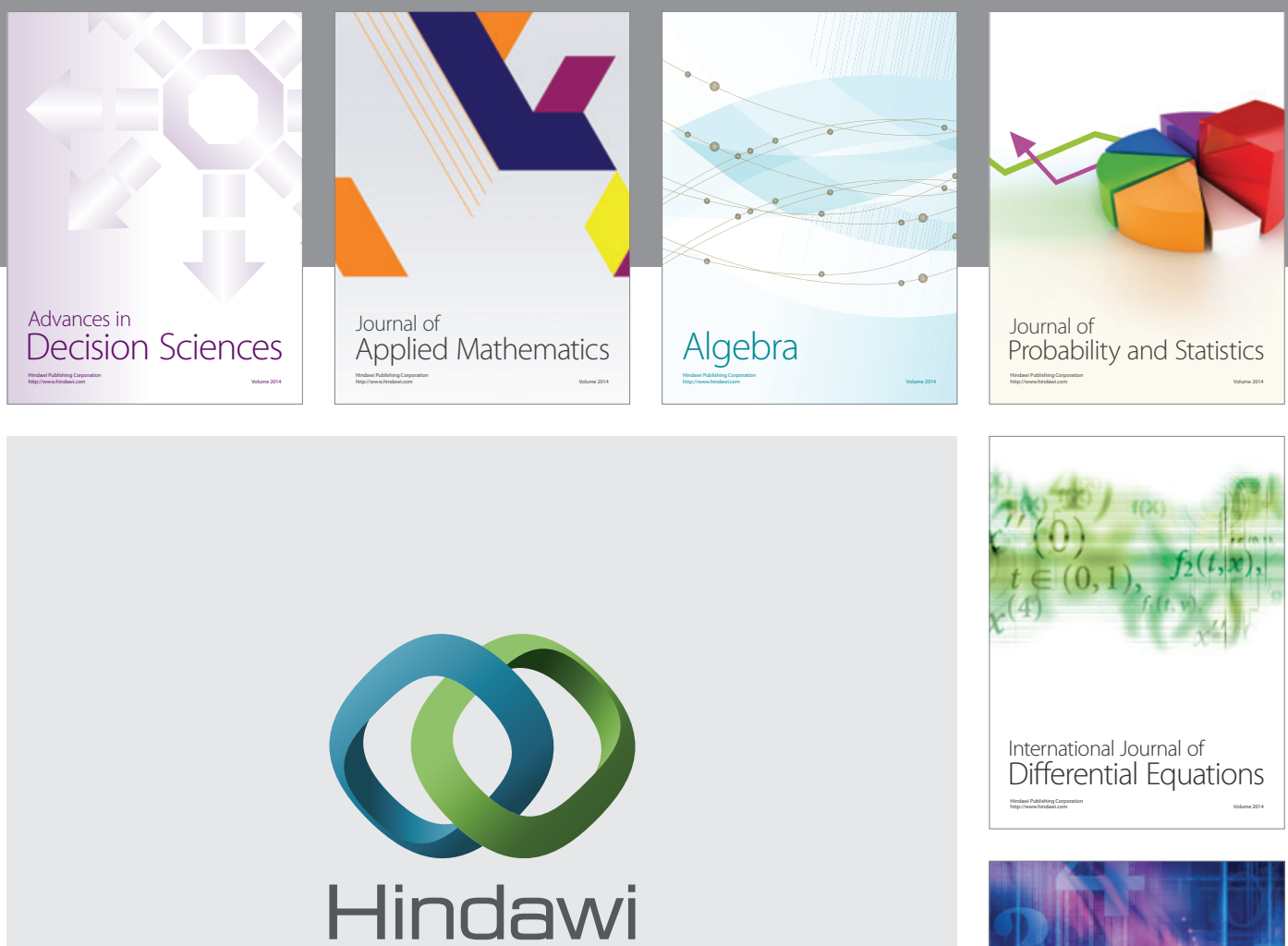

Submit your manuscripts at http://www.hindawi.com
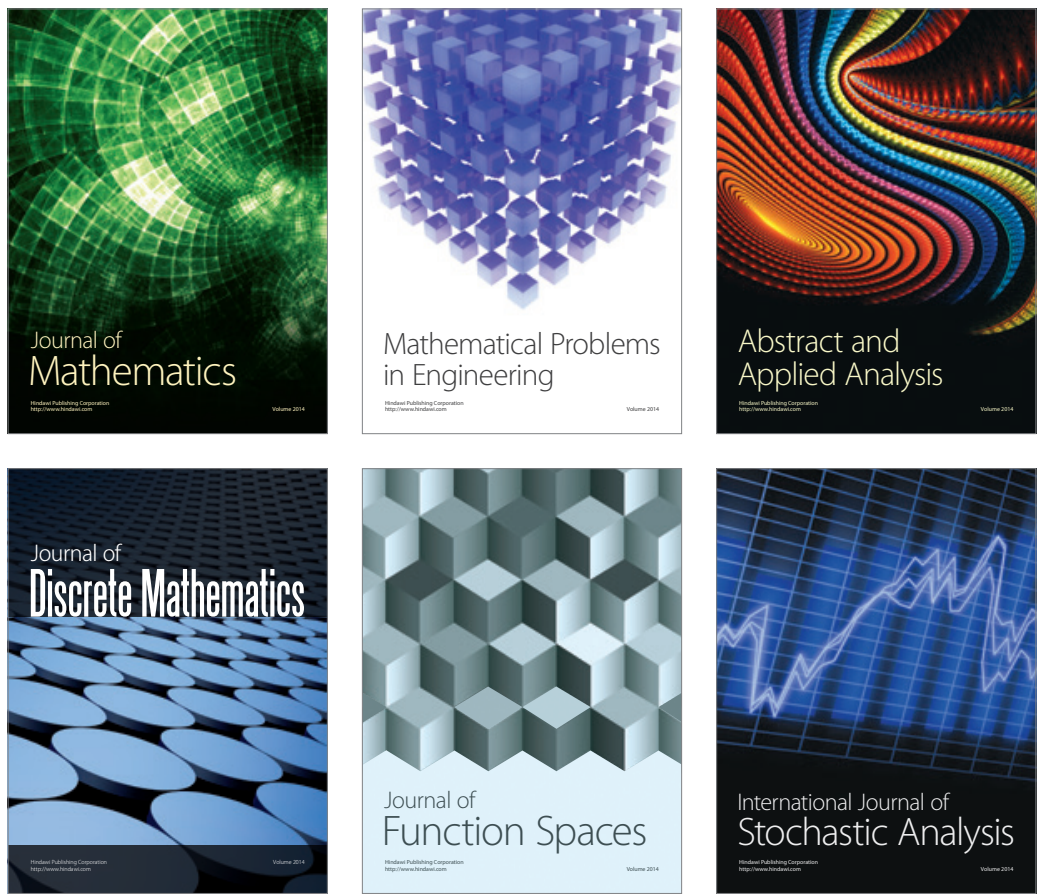

Journal of

Function Spaces

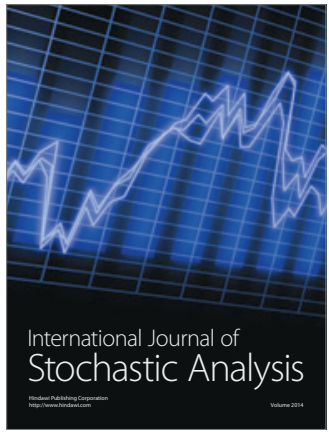

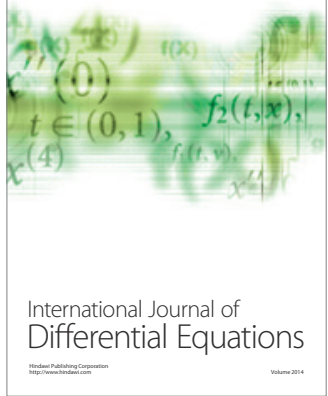
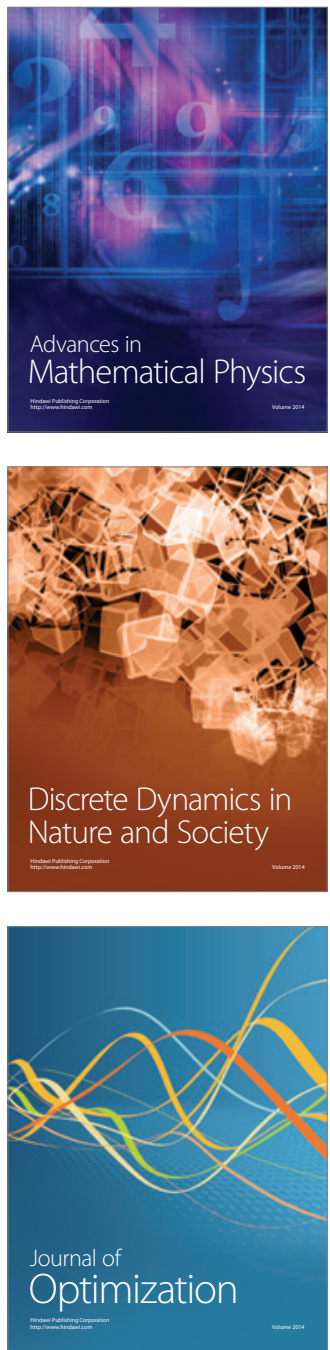